\title{
AVALIAÇÃO DOS RISCOS À SAÚDE DOS TRABALHADORES DE ENFERMAGEM DO PRONTO SOCORRO DE UM HOSPITAL UNIVERSITÁRIO
}

\author{
João Carlos Pereira Angeli ${ }^{1}$ \\ Francisco Rosemiro Guimarães Ximenes Neto ${ }^{2}$ \\ Isabel Cristina Kowal Olm Cunha ${ }^{1}$
}

\author{
https://orcid.org/0000-0001-7739-9118 \\ https://orcid.org/0000-0002-7905-9990 \\ http://orcid.org/0000-0001-6374-5665
}

Objetivo: Identificar o conhecimento dos trabalhadores de Enfermagem do pronto socorro de um hospital universitário acerca dos riscos laborais a que estão submetidos. Método: Estudo exploratório sob a abordagem quantitativa, onde aplicou-se um questionário para 137 profissionais de Enfermagem (48 enfermeiros, 37 técnicos de enfermagem e 52 auxiliares de enfermagem) do Pronto Socorro de um Hospital Universitário. Resultados: Os sujeitos do estudo são predominantemente do sexo feminino (70,8\%), na faixa etária de 26 a 35 anos (43,1\%), com até cinco anos de trabalho no pronto socorro ( $81,6 \%)$ e atuando no turno noturno (41,6\%). Dos riscos, os mais apontados foram os biológicos como bactérias, vírus, sangue, e secreções, pelas três categorias profissionais. Seguiram-se os riscos físicos com material perfuro cortante, manutenção precária e ruídos; os químicos medicamentos, poeira e desinfetantes; e os ergonômicos levantar e sustentar pacientes e andar muito pelo setor. Conclusão: Os profissionais reconhecem o principal risco envolvido em sua prática assistencial como sendo biológico. Esses resultados são importantes para nortear ações na gestão que visem ações preventivas.-

Descritores: Riscos Ocupacionais; Serviço Hospitalar de Engenharia e Manutenção; Serviços Médicos de Emergência; Hospitais Universitários.

\section{EVALUATION OF HEALTH RISKS FOR NURSING WORKERS IN THE EMERGENCY DEPARTMENT OF A UNIVERSITY HOSPITAL}

Objective: To identify the health risks of nursing workers in the emergency department of a university hospital. Method: Exploratory study with quantitative approach, using a questionnaire applied in 137 nursing workers (48 nurses, 37 nursing technicians and 52 nursing assistants) from the Emergency Room of an university hospital center. Results: The sample consisted of predominantly female (70.8\%), ages 26 to 35 years old (43.1\%), with up to five years of work in the emergency room (81.6\%) and working in the night shift (41.6\%). The main risk cited by all professionals was Biological, exemplified by bacteria, viruses, blood, and secretions. Others risks were also remembered, such as the Physical ones: use of sharp-perforating material, poor maintenance of the environment and noise; Chemical risks described as contact with medical drugs, dust and disinfectants; and the Ergonomic ones, like to raise and to support patients and walk around the sector a lot. Conclusion: Nursing Professionals recognize the main risk involved in their daily practice as being biological. These results are important to guide further preventive actions.

Descriptors: Occupational Risks; Maintenance and Engineering, Hospital; Emergency Medical Services; Hospitals, University.

\section{EVALUACIÓN DE RIESGOS DE SALUD DE TRABAJADORES DE ENFERMERÍA EN UN HOSPITAL UNIVERSITARIO}

Objetivo: identificar los riesgos para la salud de los trabajadores de enfermería en el departamento de emergencias de un hospital universitario. Método: estudio exploratório con enfoque cuantitativo, desarrollado a partir de un cuestionario para 137 profesionales de enfermería (48 enfermeras, 37 técnicas de enfermería y 52 auxiliares de enfermería) de la sala de emergencias de uno hospital universitario. Resultados: Los sujetos del estudio son predominantemente mujeres (70.8\%), de 26 a 35 años (43.1\%), con hasta cinco años de trabajo en la sala de emergencias (81.6\%) y trabajando en el turno nocturno (41,6\%). De los riesgos, los más destacados fueron los Biologicos, como bacterias, virus, sangre y secreciones, por las tres categorias profesionales. A seguir fueran los riesgos Fisicos con lo material perforante, mala conservación del área física y ruido; los Quimicos con las drogas quimicas, polvo y desinfectantes; y los Ergonómicos com la movilizacion y apoyo a los pacientes y se muever mucho por el sector. Conclusión: Los profesionales reconocen que el principal riesgo involucrado en su práctica de cuidado es biológico. Estos resultados son importantes para guiar las acciones de gestión dirigidas a acciones preventivas Descriptores: Riesgos Laborales; Servicio de Mantenimiento e Ingeniería en Hospital; Servicios Médicos de Urgencia; Hospitales Universitarios.

${ }^{1}$ Grupo de Estudos e Pesquisa em Administração em Saúde e Gerenciamento de Enfermagem - GEPAG da Universidade Federal de São Paulo, SP, Brasil. 2Universidade Vale do Acaraú, Sobral, CE, Brasil.

Autor correspondente: Isabel Cristina Kowal Olm Cunha - Email: isabel.cunha@cofen.gov.br

Recebido: 17/05/2020 - Aceito: 02/11/2020 


\section{INTRODUÇÃO}

O setor saúde, produtor de serviços de diversas especialidades, a exemplo da urgência e emergência, possui especificidades na atuação dos profissionais que nele trabalham, quer pela multiplicidade do escopo de práticas ou pelos riscos constantes a que estão expostos. O hospital como ambiente laboral reconhecidamente insalubre, expõe os trabalhadores a diversos riscos, agravos e doenças ${ }^{1-2}$.

Os profissionais de Enfermagem (enfermeiros, técnicos e auxiliares de enfermagem) constituem a maior força de trabalho, estando em contato direto na linha de frente com a clientela, expondo-os a diversos riscos e vulnerabilizando-os a contrair doenças durante o processo de cuidado ${ }^{2-4}$.

$\mathrm{Na}$ área hospitalar a equipe de Enfermagem representa $56,5 \%$ de um coletivo de mais de dois milhões de profissionais. Nos hospitais universitários esse percentual chega a $10,3 \%$. Por ser o maior contingente de profissionais do macro Setor Saúde, os trabalhadores da Enfermagem estão mais expostos a determinados fatores ou agentes de riscos químicos, físicos, biológicos, psicológicos, ergonômicos e organizacionais, sobretudo quando atuam em ambiente sem as condições adequadas de trabalho, bastante insalubres e sem a disponibilidade de Equipamentos de Proteção Individual (EPI)2. Os riscos à saúde dos trabalhadores se processam na realização de cada atividade durante o labor, a partir da sua exposição a atividades perigosas e insalubres ${ }^{6}$.

As substâncias quimicas tóxicas, as poeiras, os ruidos, a vibração, o calor ou o frio excessivo, a tensão, as radiações, os microrganismos, as posturas viciosas, os movimentos repetitivos, a sobrecarga, a exigência excessiva e a monotonia que acontece em decorrência das condições de trabalho, são importantes fatores de riscos que podem ocasionar lesão, doença, inaptidão ou afetar o bem estar e a saúde mental ${ }^{5}$.

A exposição às diferentes tipologias de risco pode ocorrer em qualquer setor do hospital, sendo ampliado no pronto socorro, onde são assistidos casos de urgência e emergência, estando o profissional muitas vezes atuando no limitrofe entre salvar vidas e vivenciar o findo desta, expondo-se a diversos tipos de matérias orgânicas, quase sempre em espaços que foram mal projetados, em construções adaptadas, sem conservação ou operados sem a devida técnica.

Com isso, surgiu a seguinte indagação: Quais são os riscos a que os profissionais da equipe de Enfermagem estão submetidos num pronto socorro de um hospital universitário? Desta maneira, este estudo buscou identificar os ris- cos à saúde dos trabalhadores de Enfermagem do pronto socorro de um hospital universitário e descrever suas características sociodemográficas.

\section{MÉTODO}

\section{Tipo de estudo}

Estudo exploratório, sob a abordagem quantitativa.

\section{Local do estudo}

A pesquisa foi realizada no Pronto Socorro de um Hospital Universitário na cidade de São Paulo. Trata-se de um hospital privado gerenciado por universidade pública, com 748 leitos, que possui um pronto socorro de atendimento terciário, referência do Sistema Único de Saúde (SUS) para toda a cidade de São Paulo, realizando perto de 1.000 atendimentos/dia. O pronto socorro tem o setor de adulto e infantil.

A estrutura física deste pronto socorro é bastante antiga apesar de ter passado por várias reformas ao longo dos anos. Possui 28 salas de atendimento peculiares (emergência, pequenas cirurgias, curativos) além das necessárias para a equipe de trabalho (farmácia, postos de enfermagem, área administrativa, depósitos de materiais de limpeza, consultórios), e os leitos para repouso divididos em áreas masculina e feminina que atendem à regulamentação estabelecida.

Por ser um hospital universitário atuam neste setor além do seu corpo de servidores públicos e celetistas, professores e estudantes dos cursos de Enfermagem, Medicina, Biomedicina, Fonoaudiologia, entre outros, tanto em nível de graduação quanto da pós-graduação lato sensu e stricto sensu.

\section{Participantes do estudo}

Para o estudo foram convidados a participar todos os 194 profissionais da equipe de Enfermagem (48 enfermeiros, 38 técnicos de enfermagem e 108 auxiliares de enfermagem) dos diferentes turnos de atendimento. Como critério de inclusão o profissional deveria trabalhar há mais de seis meses. Foram excluídos do estudo, os profissionais que estivessem de licença durante a coleta dos dados.

Participaram da pesquisa uma amostra de 48 enfermeiros, 37 técnicos de enfermagem e 52 auxiliares de enfermagem, totalizando 137 respondentes.

\section{Coleta de dados}

A coleta de dados ocorreu de novembro de 2014 a agosto de 2015, utilizando um questionário, envolvendo variáveis contendo características sociodemográficas e referentes a turno e tempo de trabalho, além dos riscos 
relacionados ao trabalho (biológicos, físicos, químicos e ergonômicos). O questionário continha questões fechadas (com itens de múltipla escolha) e abertas, com a possibilidade de apresentar outros riscos que não foram relacionados.

\section{Procedimentos de análise e tratamento dos dados}

Os dados dos questionários foram transpostos para planilha Excel® 2010 e analisados estatisticamente. A análise descritiva dos dados incluiu o cálculo de frequências absolutas e percentuais. Para as existências de associações entre duas variáveis categóricas utilizou-se o teste de Qui-Quadrado, ou alternativamente em casos de amostras pequenas o teste exato de Fisher. O software estatístico utilizado para a análise foi o SPSS 20.0

Os riscos foram avaliados levando em conta a probabilidade de este causar danos aos trabalhadores e o nivel de gravidade da lesão que possa ocorrer ${ }^{7}$. Os riscos foram categorizados conforme a Norma Regulamentadora $n$ 의 9 sobre "Riscos Ambientais e dá outras providências" de 29 de dezembro de $1994^{8}$, que são:

- Riscos Físicos: ruidos, vibrações, radiações ionizantes, radiações não ionizantes, frio, calor, pressões anormais, umidade etc.;

- Riscos Químicos: poeiras, fumos, névoas, neblinas, gases vapores, substâncias, compostas ou produtos químicos em geral etc.;

- Riscos Biológicos: vírus, bactérias, protozoários, fungos, parasitas, bacilos etc.;

- Riscos de Ergonômicos: esforço físico intenso, levantamento e transporte manual de peso, exigência de postura inadequada, controle rígido de produtividade, imposição de ritmos excessivos, trabalho em turno e noturno, jornadas de trabalho prolongadas, monotonia e repetitividade e outras situações causadoras de stress físico e/ou psíquico.

\section{Aspectos éticos}

Esta pesquisa respeitou os princípios éticos e legais das pesquisas envolvendo seres humanos, visando assegurar os direitos dos participantes da pesquisa9, sendo que seu protocolo foi submetido ao Comitê de Ética e Pesquisa (CEP) institucional e aprovado sob $n$ ㅇ CAAE 31475114.1.0000.5505 e ParecerNo.680.388. Foi autorizado ainda pela Diretoria da Enfermagem e Científica do referido Hospital Universitário. Todos os entrevistados assinaram o Termo de Consentimento Livre e Esclarecido (TCLE).

\section{RESULTADOS}

Dos 137 profissionais de Enfermagem do estudo, 35\% são enfermeiros, $27 \%$ técnicos de enfermagem e $38 \%$ auxiliares de enfermagem. A Tabela 1 apresenta um breve perfil da Equipe de Enfermagem do pronto socorro estudado.

Tabela 1 Distribuição dos profissionais de Enfermagem segundo características sociodemográficas e de trabalho.

\begin{tabular}{|c|l|l|}
\hline Variáveis & N & \% \\
\hline Sexo & & \\
\hline Masculino & 40 & 29,2 \\
Feminino & 97 & 70,8 \\
\hline Total & 137 & 100,0 \\
\hline
\end{tabular}

Faixa Etária (anos)

\begin{tabular}{|c|c|c|}
\hline 22 a 25 & 13 & 9,5 \\
\hline 26 a 30 & 29 & 21,2 \\
\hline 31 a 35 & 30 & 21,9 \\
\hline 36 a 40 & 24 & 17,5 \\
\hline 41 a 45 & 10 & 7,3 \\
\hline 46 a 50 & 11 & 8,0 \\
\hline 51 a 55 & 4 & 2,9 \\
\hline 56 a 60 & 11 & 8,0 \\
\hline Sem informação & 5 & 3,7 \\
\hline Total & 137 & 100,0 \\
\hline \multicolumn{3}{|c|}{$\begin{array}{l}\text { Tempo de Trabalho no Pronto Socorro } \\
\text { (anos) }\end{array}$} \\
\hline Menos de 2 anos & 50 & 36,5 \\
\hline 2 a 5 anos & 48 & 35,1 \\
\hline 6 a 10 anos & 14 & 10,2 \\
\hline 11 a 15 anos & 14 & 10,2 \\
\hline Acima de 15 anos & 11 & 8,0 \\
\hline Total & 137 & 100,0 \\
\hline \multicolumn{3}{|l|}{ Turno de Trabalho } \\
\hline Manhã & 35 & 25,5 \\
\hline Tarde & 30 & 21,9 \\
\hline Manhã/Tarde & 15 & 11,0 \\
\hline Noturno & 57 & 41,6 \\
\hline Total & 137 & 100,0 \\
\hline
\end{tabular}

O estudo mostra na Tabela 1 a predominância de profissionais do sexo feminino (70,8\%), na faixa etária de 26 a 35 anos (43,1\%), com até cinco anos de trabalho no pronto socorro $(81,6 \%)$ e atuando no turno noturno $(41,6 \%)$. 
A Figura 1 apresenta os principais riscos identificados por categoria e tipo.

Figura 1 Tipos de riscos percebidos pelos profissionais de Enfermagem no pronto socorro.

A Figura 1 mostra os riscos que predominaram neste estudo foram: físico - material perfuro cortante (92\%); quí-

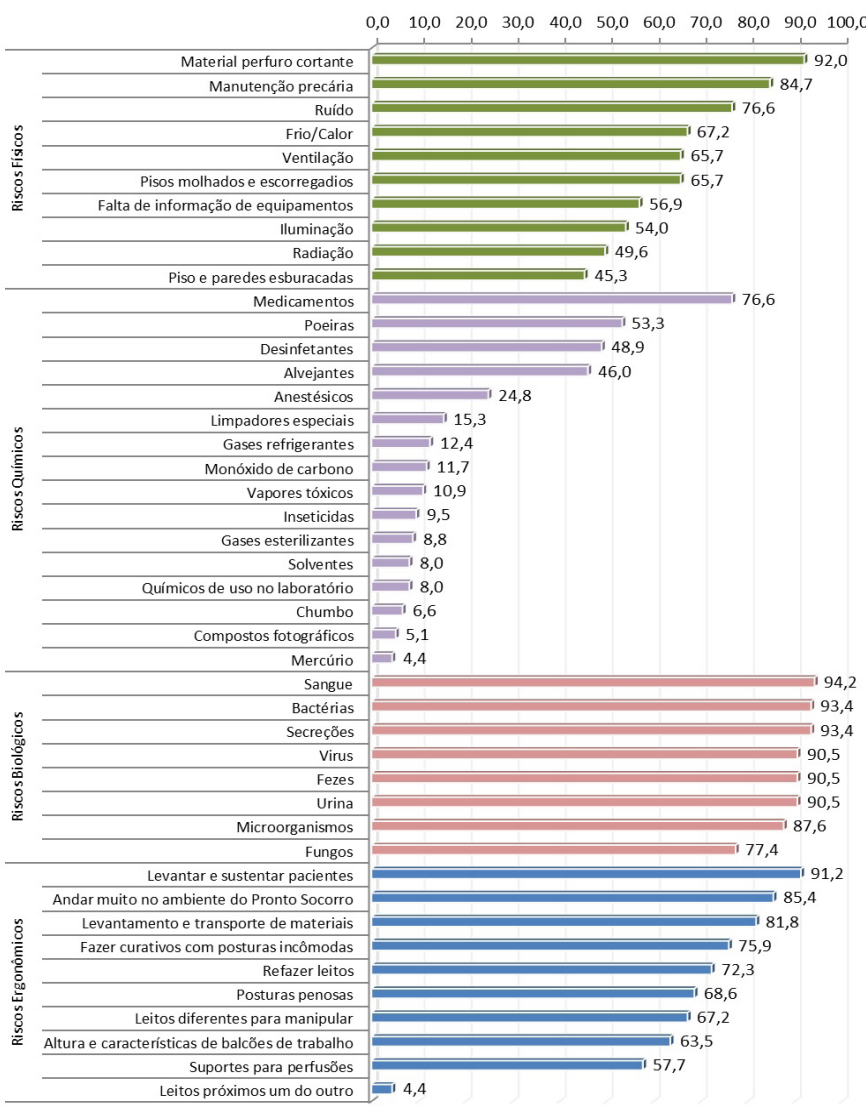

mico - medicamentos (76,6\%); biológico - sangue 94,3\%; e ergonômicos - levantar e sustentar pacientes (91,2\%).

A Tabela 2 apresenta a estratificação dos riscos por categoria profissional da Enfermagem.

Tabela 2 Riscos referidos por categoria profissional da Enfermagem.

\begin{tabular}{|c|c|c|c|c|c|c|c|c|c|}
\hline \multirow{3}{*}{$\begin{array}{l}\text { Variáveis por } \\
\text { Categoria de } \\
\text { Risco e Tipo }\end{array}$} & \multicolumn{6}{|c|}{ Categoria } & \multirow{2}{*}{\multicolumn{2}{|c|}{ Total }} & \\
\hline & \multicolumn{2}{|c|}{$\begin{array}{l}\text { Enfer- } \\
\text { meiro }\end{array}$} & \multicolumn{2}{|c|}{ Técnico } & \multicolumn{2}{|c|}{ Auxiliar } & & & $\mathrm{p}^{*}$ \\
\hline & $\mathrm{n}$ & $\%$ & $n$ & $\%$ & $\mathrm{n}$ & $\%$ & $\mathrm{n}$ & $\%$ & \\
\hline
\end{tabular}

Riscos

Fisicos

\begin{tabular}{lccccccccc}
$\begin{array}{l}\text { Material } \\
\text { perfuro } \\
\text { cortante }\end{array}$ & 45 & 93,8 & 32 & 86,5 & 49 & 94,2 & 126 & 92,0 & $0,413^{a}$ \\
$\begin{array}{l}\text { Manutenção } \\
\text { precária }\end{array}$ & 38 & 79,2 & 33 & 89,2 & 45 & 86,5 & 116 & 84,7 & 0,398 \\
\hline $\begin{array}{l}\text { Ruido } \\
\text { Frio/Calor }\end{array}$ & 41 & 85,4 & 27 & 73,0 & 37 & 71,2 & 105 & 76,6 & 0,200 \\
\hline
\end{tabular}

\begin{tabular}{|c|c|c|c|c|c|c|c|c|c|}
\hline Ventilação & 31 & 64,6 & 23 & 62,2 & 36 & 69,2 & 90 & 65.7 & 0,771 \\
\hline $\begin{array}{l}\text { Pisos molha- } \\
\text { dos e escor- } \\
\text { regadios }\end{array}$ & 29 & 60,4 & 26 & 70,3 & 35 & 67,3 & 90 & 65,7 & 0,607 \\
\hline $\begin{array}{l}\text { Falta de } \\
\text { informação } \\
\text { de equipa- } \\
\text { mentos }\end{array}$ & 30 & 62,5 & 20 & 54,1 & 28 & 53,8 & 78 & 56,9 & 0,627 \\
\hline Iluminação & 26 & 54,2 & 19 & 51,4 & 29 & 55,8 & 74 & 54,0 & 0,918 \\
\hline Radiação & 30 & 62,5 & 21 & 56,8 & 17 & 32,7 & 68 & 49,6 & 0,007 \\
\hline $\begin{array}{l}\text { Piso e } \\
\text { paredes es- } \\
\text { buracadas }\end{array}$ & 23 & 47,9 & 17 & 45,9 & 22 & 42,3 & 62 & 45,3 & 0,849 \\
\hline \multicolumn{10}{|l|}{$\begin{array}{l}\text { Riscos } \\
\text { Químicos }\end{array}$} \\
\hline $\begin{array}{l}\text { Medicamen- } \\
\text { tos }\end{array}$ & 37 & 77,1 & 29 & 78,4 & 39 & 75,0 & 105 & 76,6 & 0,930 \\
\hline Poeiras & 27 & 56,2 & 21 & 56,8 & 25 & 48,1 & 73 & 53,3 & 0,633 \\
\hline $\begin{array}{l}\text { Desinfetan- } \\
\text { tes }\end{array}$ & 26 & 54,2 & 17 & 45,9 & 24 & 46,2 & 67 & 48,9 & 0,664 \\
\hline Alvejantes & 21 & 43.8 & 15 & 40,5 & 27 & 51,9 & 63 & 46,0 & 0,528 \\
\hline Anestésicos & 15 & 31,2 & 10 & 27,0 & 9 & 17,3 & 34 & 24,8 & 0,255 \\
\hline $\begin{array}{l}\text { Limpadores } \\
\text { especiais }\end{array}$ & 10 & 20,8 & 4 & 10,8 & 7 & 13,5 & 21 & 15,3 & 0,398 \\
\hline $\begin{array}{l}\text { Gases refri- } \\
\text { gerantes }\end{array}$ & 8 & 16,7 & 4 & 10,8 & 5 & 9,6 & 17 & 12,4 & 0,532 \\
\hline $\begin{array}{l}\text { Monóxido de } \\
\text { carbono }\end{array}$ & 6 & 12,5 & 6 & 16,2 & 4 & 7,7 & 16 & 11,7 & 0,456 \\
\hline $\begin{array}{l}\text { Vapores } \\
\text { tóxicos }\end{array}$ & 6 & 12,5 & 6 & 16,2 & 3 & 5,8 & 15 & 10,9 & 0,272 \\
\hline $\begin{array}{l}\text { Gases este- } \\
\text { rilizantes }\end{array}$ & 6 & 12,5 & 4 & 10,8 & 2 & 3.8 & 12 & 8,8 & $0,246^{a}$ \\
\hline Solventes & 6 & 12,5 & 3 & 8,1 & 2 & 3,8 & 11 & 8,0 & $0,276^{a}$ \\
\hline \multicolumn{10}{|l|}{$\begin{array}{l}\text { Riscos } \\
\text { Biológicos }\end{array}$} \\
\hline Sangue & 44 & 91,7 & 35 & 94,6 & 50 & 96,2 & 129 & 94,2 & $0,601^{a}$ \\
\hline Bactérias & 46 & 95,8 & 34 & 91,9 & 48 & 92,3 & 128 & 93.4 & $0,750^{a}$ \\
\hline Secreções & 44 & 91,7 & 35 & 94,6 & 49 & 94,2 & 128 & 93,4 & $0,828^{a}$ \\
\hline Virus & 46 & 95,8 & 31 & 83,8 & 47 & 90,4 & 124 & 90,5 & $0,170^{a}$ \\
\hline Fezes & 44 & 91,7 & 33 & 89,2 & 47 & 90,4 & 124 & 90,5 & $0,935^{a}$ \\
\hline Urina & 44 & 91,7 & 33 & 89,2 & 47 & 90,4 & 124 & 90,5 & $0,935^{a}$ \\
\hline $\begin{array}{l}\text { Microrga- } \\
\text { nismos }\end{array}$ & 44 & 91,7 & 31 & 83,8 & 45 & 86,5 & 120 & 87,6 & 0,527 \\
\hline Fungos & 43 & 89,6 & 25 & 67,6 & 38 & 73,1 & 106 & 77,4 & 0,036 \\
\hline \multicolumn{10}{|l|}{$\begin{array}{l}\text { Riscos Ergo- } \\
\text { nômicos }\end{array}$} \\
\hline $\begin{array}{l}\text { Levantar e } \\
\text { sustentar } \\
\text { pacientes }\end{array}$ & 42 & 87,5 & 32 & 86,5 & 51 & 98,1 & 125 & 91,2 & $0.066^{a}$ \\
\hline $\begin{array}{l}\text { Andar muito } \\
\text { no ambiente } \\
\text { do Pronto } \\
\text { Socorro }\end{array}$ & 42 & 87,5 & 32 & 86,5 & 43 & 82,7 & 117 & 85,4 & 0,775 \\
\hline $\begin{array}{l}\text { Levanta- } \\
\text { mento e } \\
\text { transporte } \\
\text { de materiais }\end{array}$ & 40 & 83,3 & 28 & 75,7 & 44 & 84,6 & 112 & 81,8 & 0,527 \\
\hline $\begin{array}{l}\text { Fazer cura- } \\
\text { tivos com } \\
\text { posturas } \\
\text { incômodas }\end{array}$ & 35 & 72,9 & 30 & 81,1 & 39 & 75,0 & 104 & 75,9 & 0,670 \\
\hline $\begin{array}{l}\text { Refazer } \\
\text { leitos }\end{array}$ & 32 & 66,7 & 29 & 78,4 & 38 & 73,1 & 99 & 72,3 & 0,482 \\
\hline
\end{tabular}




\begin{tabular}{|c|c|c|c|c|c|c|c|c|c|}
\hline $\begin{array}{l}\text { Posturas } \\
\text { penosas }\end{array}$ & 33 & 68,8 & 24 & 64,9 & 37 & 71,2 & 94 & 68,6 & 0,820 \\
\hline $\begin{array}{l}\text { Leitos dife- } \\
\text { rentes para } \\
\text { manipular }\end{array}$ & 32 & 66,7 & 25 & 67,6 & 35 & 67,3 & 92 & 67,2 & 0,996 \\
\hline $\begin{array}{l}\text { Altura e ca- } \\
\text { racteristicas } \\
\text { de balcões } \\
\text { de trabalho }\end{array}$ & 32 & 66,7 & 23 & 62,2 & 32 & 61,5 & 87 & 63,5 & 0,851 \\
\hline $\begin{array}{l}\text { Suportes } \\
\text { para perfu- } \\
\text { sões }\end{array}$ & 24 & 50,0 & 26 & 70,3 & 29 & 55,8 & 79 & 57,7 & 0,162 \\
\hline $\begin{array}{l}\text { Leitos próxi- } \\
\text { mos um do } \\
\text { outro }\end{array}$ & 3 & 6,2 & 2 & 5,4 & 1 & 1,9 & 6 & 4,4 & $0,576^{a}$ \\
\hline
\end{tabular}

*p - nivel descritivo do teste de Qui-Quadrado ou exato de Fisher.

\section{DISCUSSÃO}

\section{- Perfil da Equipe de Enfermagem}

No Brasil, segundo dados da Pesquisa do Perfil da Enfermagem no Brasil (PPEB) 7,7\% dos profissionais atuam em pronto socorro ${ }^{10}$. Este estudo mostra a predominância de $70,8 \%$ dos profissionais do sexo feminino. Historicamente, as Equipes de Enfermagem são formadas por mulheres, o que também se confirma nesta pesquisa. Estudos apontam que mais de $90 \%$ dos profissionais de Enfermagem das unidades de Pronto Socorro são do sexo feminino ${ }^{11-12}$. A PPEB aponta que o feminino na Enfermagem é uma tradição histórica e cultural ${ }^{10}$

A partir do construto da sociologia das profissões, Machado et al. ${ }^{510}$ estabelecem uma categorização de fases da vida profissional, que leva em conta a idade, o tempo de formado até a entrada do trabalhador no mercado de trabalho, sendo: 1a Fase, denominada de "Início da vida profissional", refere-se aqueles com até 25 anos de idade; $2 \underline{a}$ Fase, chamada de "Formação Profissional", 26 a 35 anos de idade; 3a Fase, denominada de "Maturidade profissional", encontram-se os sujeitos com idade entre 36 e 50 anos; 4a - Fase, definida como "Desaceleração profissional", de 51 a 60 anos; e a 5a Fase, da "Aposentadoria", estão aqueles com idade acima de 61 anos. Nesta pesquisa, predomina uma equipe de Enfermagem na fase de "formação profissional", 43,1\%; seguida da fase de "maturidade profissional", $32,8 \%$. Na PPEB assim como esta, predominaram as fases de maturidade profissional (40\%) e de formação profissional (38\%), o que caracteriza ser a Enfermagem uma profissão em pleno rejuvenescimento ${ }^{10,513}$. Este estudo aponta ainda, que $70,1 \%$ dos profissionais são adultos jovens, entre 20 e 40 anos.

Quanto ao tempo de atuação no pronto socorro, $71,6 \%$ atuam até 10 anos. Estudo desenvolvido nas Unidades de
Pronto Atendimento de um município do interior do Estado de São Paulo, com 128 profissionais de Enfermagem, apontou que $49 \%$ atuavam no setor entre seis meses e oito $\operatorname{anos}^{11}$.

Os profissionais que já estão na ativa há certo tempo apresentam uma maior expertise e destreza manual, para o desenvolvimento do processo de cuidar, sobretudo para a realização de procedimentos que exijam técnicas com mais acurácia, tanto para a segurança do paciente, quanto para a biossegurança de ambos. O conhecimento aliado a uma boa prática clínica reduz os riscos e o nível de insalubridade para os trabalhadores da Enfermagem. O que refletirá na qualidade do atendimento da clientela, favorecendo o methor desenvolvimento das competências profissionais. Ao mesmo tempo, pode contribuir com que o profissional se sinta mais confiante e relaxe o cuidado, pondo em riscos ambos - trabalhador-cliente.

Observa-se que $41,6 \%$ dos respondentes, trabalham no período noturno. Estudos desenvolvidos no mesmo setor, um no interior de São Paulo $(40 \%)^{11}$ apontou dado semelhante, e em Maringá - PR, 31,6\%12. O trabalho noturno permite que as instituições de saúde ofertem serviços, sobretudo de urgência e emergência de modo ininterrupto, a semana toda, para atender demandas específicas, a exemplo dos agravos por causas externas e episódios agudos de diferentes doenças.

O plantão noturno tem algumas peculiaridades diferentes dos demais, exigindo dos profissionais de Enfermagem maior estado de alerta e atenção, além de ser um potencializador nas repercussões físicas e psíquicas, trazendo implicações na saúde geral e alterações nas funções orgânicas destes profissionais ${ }^{14-15}$. Segundo autores, "turnos de trabalho mais longos e em horários contrários ao ciclo circadiano implica em um menor tempo de descanso, fadiga excessiva e questões que refletem diretamente na qualidade do serviço prestado, envolvendo o ambiente de trabalho"14.

A redução das horas de sono diárias e a impossibilidade de recuperá-las após a jornada de trabalho noturna são importantes fatores de desgaste dos trabalhadores ${ }^{15}$, que associados com o excesso de demanda do plantão, a sobrecarga de trabalho, múltiplos empregos/jornadas de trabalho e o estresse, podem contribuir para vulnerabilizar o trabalhador ainda mais aos riscos laborais e a amplitude e a magnitude dos acidentes de trabalho.

\section{- Riscos que a Equipe de Enfermagem está exposta}

Independentemente do local e da atividade laboral exercida, o trabalho expõe os trabalhadores a diversos ris- 
cos, que são potencializados a depender da ambiência onde este se desenvolve, as condições de trabalho a que estão submetidos, e se estes têm acesso e sabem utilizar os EPI.

Para a Organização Internacional do Trabalho (OIT) ${ }^{7}$, os riscos incidem sobre a possibilidade ou a probabilidade de um trabalhador ficar ferido ou sofrer alguns eventos adversos a sua saúde, quando expostos ao perigo. Todavia, para detecção e avaliação dos riscos, deve ser identificado o que pode afetar os trabalhadores e o ambiente laboral, como forma de desenvolver medidas para prevenção e proteção de acidentes de trabalho.

Para tal, o "reconhecimento dos riscos ambientais é uma etapa fundamental do processo que servirá de base para a tomada de decisões quanto às ações de prevenção, eliminação ou controle" destes ${ }^{16}$. No entanto, “... os fatores de risco presentes nos locais de trabalho não devem ser compreendidos de forma isolada e estanque. Ao contrário, é necessário apreender a forma como eles acontecem na dinâmica global e cotidiana do processo de trabalho"17.

Pois, segundo o Ministério da Saúde ${ }^{18}$ "os locais de trabalho, pela própria natureza da atividade desenvolvida e pelas características de organização, relações interpessoais, manipulação ou exposição a agentes físicos, químicos, biológicos, situações de deficiência ergonômica ou riscos de acidentes, podem comprometer a saúde e a segurança do trabalhador em curto, médio e longo prazo, provocando lesões imediatas, doenças ou a morte".

Neste estudo foram identificados diversos tipos de riscos associados a quatro categorias básicas (físicos, químicos, biológicos e ergonômicos). Verifica-se que para os riscos físicos, ressalta-se que as maiores porcentagens foram para material perfuro cortante (92,0\%), manutenção precária da unidade (84,7\%), ruído (76,6\%), frio/calor $(67,2 \%)$, ventilação $(65,7 \%)$ e pisos molhados e escorregadios (65,7\%). Estudos mostram que os principais riscos físicos no ambiente de trabalho estão associados a materiais perfuro cortantes ${ }^{19-21}$. Com exceção das radiações ionizantes, os riscos de natureza física são geralmente fáceis de reconhecer, pois atuam diretamente sobre os sentidos, voltados para algum tipo de energia ${ }^{18}$.

Um estudo identificou 60\% dos profissionais apontaram a ventilação/climatização e a temperatura como inadequadas nos locais de trabalho, dados semelhantes a este, em que $67,2 \%$ dos profissionais de enfermagem apontaram o frio/calor e $65,7 \%$ de ventilação ${ }^{22}$. Estudo que apontou os riscos físicos percebidos pelos trabalhadores da enfermagem de Hospital Universitário do Rio de Janeiro, 66,9\% apontam a exposição à radiação, 59,3\% a exposição ao ruido, $41,6 \%$ a exposição a temperatura inadequada, e $37,6 \%$ aos perfuro cortantes ${ }^{23}$

O profissional da saúde que possui uma ambiência de trabalho agradável, sem muito estresse e muitas cobranças, com estrutura física satisfatória, iluminação e ventilação adequada, espaço para repouso, manuseio adequado dos perfuro cortantes, com uso correto de EPI e destino dos Resíduos Sólidos de Serviços de Saúde (RSSS) com descarte adequado, reduz os riscos físicos e, consequentemente, os acidentes de trabalho, seja por agente físico, biológico ou de outra categoria; ampliando assim a segurança no trabalho.

Corroboramos com a Política Nacional de Humanização. a HUMANIZASUS, ao definir que a ambiência de um serviço de saúde "compreende o espaço físico, social, profissional e de relações interpessoais que deve estar em sintonia com um projeto de saúde voltado para a atenção acolhedora, resolutiva e humana", com a organização de espaços saudáveis a partir dos seguintes eixos principais: " 1 . $O$ espaço que visa a confortabilidade; 2 . O espaço como ferramenta facilitadora do processo de trabalho e 3. A ambiência como espaço de encontros entre os sujeitos"24, envolvendo clientela-profissionais-trabalho-cuidado em torno de um projeto terapêutico que garanta segurança para ambos.

Para os riscos químicos o maior percentual respondido foi para medicamentos (76,6\%), poeiras $(53,3 \%)$, desinfetantes (48,9\%) e alvejantes (46,0\%). Trabalhadores hospitalares em outro estudo reconheceram sua exposição aos medicamentos (41\%) e aos desinfetantes $(23,5 \%)^{19}$. Noutra pesquisa, $22 \%$ dos trabalhadores de Enfermagem de uma UTI admitiram que estivessem expostos a produtos químicos como antibióticos, quimioterápicos e antissépticos ${ }^{20}$. Em outro predominou o contato com substância química $(34,1 \%)$ e a exposição a gases, vapores ou aerossóis $(31,7 \%)^{23}$.

Os riscos químicos se apresentam, sobretudo, nas formas líquida, gasosa ou de partículas e de poeiras minerais e vegetais. Para que um agente tóxico possa causar algum tipo de dano à saúde do trabalhador, necessita de condições adequadas para alcançar o(s) órgão(s) crítico(s) que ele pode danificar ${ }^{18}$

Os riscos biológicos foram os mais citados, e dentre estes, o sangue (94,2\%), seguido pelas bactérias e secreções com 93,4\% cada, vírus, fezes e urina com 90,5\%, cada. Em pesquisa os entrevistados mencionaram a exposição a sangue, a fluidos corpóreos, excretas e a secreções (72\%), como principal risco ${ }^{21}$. Em outra pesquisa com a Equipe de Enfermagem em hospital de Bauru, São Paulo, 55,2\% dos profissionais afirmaram ter sofrido exposição ocupacional a material biológico no decorrer de sua experiência profissional na instituição ou fora dela ${ }^{25}$. 
Os riscos biológicos compreendem as exposições dos trabalhadores aos agentes biológicos que correspondem a "microrganismos, geneticamente modificados ou não; as culturas de células; os parasitas; as toxinas e os príons"16. O ambiente hospitalar é considerado um local de trabatho complexo, insalubre e com maior risco de exposição a agentes biologicos ${ }^{25}$.

Os acidentes por material biológicos são mais incidentes no setor saúde, sobretudo com profissionais de Enfermagem, por meio do contato com mucosas, vias cutâneas e percutâneas, ou em decorrência do acidente com material perfuro cortante, o que os expõe a diversos patógenos, entre eles podemos destacar o Vírus da Hepatite B (HBV), Vírus da Hepatite C (HCV) e Vírus da Imunodeficiência Humana (HIV).

Quanto aos riscos ergonômicos foram citados em sua maioria, tendo como levantar e sustentar pacientes (91,2\%), andar muito no ambiente do pronto socorro (85,4\%), levantamento/transporte de materiais (81,8\%), fazer curativos com posturas incômodas, (75,9\%) e refazer leitos (72,3\%). Quanto aos riscos físicos pesquisas apontam 46\% para o esforço físico ${ }^{21}, 63,3 \%$ a manipulação de carga inadequada e 53,3\% necessidade de adoção de posturas adequadas do corpo $^{22}$. Os riscos ergonômicos foram percebidos de forma expressiva, por 61,6\% para posturas forçadas para realização de alguma tarefa, esforço físico que produz fadiga com $60,0 \%$, desconforto pela postura adotada por muito tempo $(59,2 \%)^{23}$. O trabalho manual, sobretudo de repetição pode causar inúmeros riscos e agravos à saúde do trabalhador ${ }^{26}$.

O modelo de como estão organizados os serviços de saúde, por conta da repetição de tarefas, levantamento de peso, sobrecarga de trabalho e estresse decorrente do processo de trabalho, pode levar ao adoecimento dos profissionais, sobretudo a Equipe de Enfermagem, que estão suscetíveis ao desenvolvimento de Lesões por Esforços Repetitivos (LER)/Distúrbios Osteomusculares Relacionados ao Trabalho (DORT), que na atualidade, representam um grave problema de saúde pública.

Os estudos sobre os riscos relacionados ao trabalho apontam que, quando eles não são submetidos a controle, levam ao aparecimento de acidentes e doenças profissionais e do trabalho ${ }^{15}$. Diversas "situações em que as exigências do trabalho não se ajustam às necessidades, expectativas ou capacidades do trabalhador, resultam em estresse como fator de risco potencial à saúde do trabalhador"9, que pode potencializar os riscos e o surgimento de agravos e doenças relacionadas ao trabalho.

Os riscos à saúde do trabalhador se processam na realização de cada atividade durante o labor, a partir da sua exposição a atividades perigosas e insalubres. Os riscos possuem relação direta com as condições de trabalho, métodos utilizados e agentes de risco a que estão expostos, sujeitando-os a possíveis efeitos adversos à sua saúde ${ }^{27}$.

Num contexto histórico de determinação ou dominação social, o processo saúde-doença-cuidado-trabalho apresenta relação estreita com as condições (estrutura e ferramentas) de como se dá o labor, com o processo de subjetivação e o nível de autonomia do trabalhador, a flexibilização da organização do trabalho e o sistema político e econômico a que este está inserido/submetido ${ }^{28}$.

Tal situação, segundo Dejours ${ }^{29}$, quando associada à monotonia do trabalho repetitivo e à falta de espaço para o exercício da criatividade pelo trabalhador, leva-os a desenvolverem mecanismos de defesa, dentre estes a auto aceleração, que os faz cessar o pensamento e, consequentemente, a consciência do desconforto, aumentando o ritmo, acarretando sofrimento patogênico e, em longo prazo, trazendo complicações para sua saúde.

Os processos produtivos a depender da estrutura, ambiência, condições e equipamentos que os trabalhadores dispõem pode expô-los e/ou vulnerabilizá-los a riscos e/ ou acidentes de trabalho, influindo diretamente no seu processo saúde-doença-cuidado-trabalho.

No processo de trabalho da Equipe de Enfermagem, os riscos à saúde dos trabalhadores podem estar relacionados também, com a divisão de social e técnica do trabatho, diferindo em qual atividade/ação a ser desempenhada. Mesmo sabedores que há a utilização de diferentes tecnologias (leves, leves-duras e duras) com forte utilização do componente relacional, da subjetividade, aliado ao conhecimento técnico-científico, a Enfermagem ainda produz um importante labor manual, que vai desde a utilização de técnicas instrumentais, a exemplo do manuseio do cliente no leito, administração de medicação, dentre outros procedimentos.

\section{Limitações do estudo}

Aspecto limitante do estudo é ter sido feito em apenas um pronto socorro hospital de hospital universitário, o que reduz a possibilidade de generalizar os dados. Todavia serve de alerta e possibilita novos estudos.

\section{Contribuições para a prática}

Identificar os riscos a que estão expostos os trabalhadores de enfermagem auxilia a gestão a direcionar ações e recursos para a melhoria das condições de trabalho, evitando o adoecimento e contribuindo para uma assistência de qualidade aos pacientes. 


\section{CONCLUSÕES}

Os profissionais de Enfermagem do estudo eram predominantemente do sexo feminino, na faixa etária de 26 a 35 anos, com até cinco anos de trabalho no pronto socorro e atuando no turno noturno. Todas as categorias profissionais mencionaram riscos e os mais citados foram: biológico - bactérias, vírus, sangue e secreções; físico - material perfuro cortante, manutenção precária e ruídos; ergonômicos - levantar e sustentar pacientes e andar muito pelo setor; e químico - medicamentos, poeira e desinfetantes.

Os resultados encontrados devem ser expostos aos trabalhadores da equipe de Enfermagem e aos dirigen- tes do Hospital Universitário, para que juntos encontrem soluções possiveis de serem implementadas, e permitir a correção das áreas que estão com inconformidades, resultando num processo laboral com menos riscos e melhor qualidade na assistência prestada.

\section{Contribuições dos autores:}

JCP Angeli e ICKO Cunha participaram da concepção e delineamento do estudo, redação e revisão do conteúdo intelectual até a versão final do manuscrito. FRG Ximenes Neto participou da redação e revisão do conteúdo intelectual até a versão final do manuscrito.

\section{REFERÊNCIAS}

1. Mendonça KM, Tipple AFV, Souza ACS, Pereira MS, Rapparini C. Acid entes com material biológico em serviços de urgência e emergência. Ciencia y Enfermeria. [Internet]. 2014 [cited 2019 Nov 6]: XX (2):65-71. Available from: http://www.redalyc.org/articulo.oa?id=370441816007.

2. Garbaccio JL, Regis WCB, Silva RMC, Estevão WG. Occupational accidents with the nursing team involved in hospital care. Cogitare Enferm. [Internet]. 2015 jan/mar [cited 2019 Nov 6]: 20(1):145-51 145. Available from: www.saude.ufpr.br/portal/ revistacogitare/v-20-n-1-2015.

3. Lima S, Oliveira GG, Rodrigues ARG, Sousa MNA. Acidentes ocupacionais com pérfurocortantes: estudo com profissionais de enfermagem. Revista Interdisciplinar em Saúde, Cajazeiras. [Internet]. 2015 Jan/Mar [cited 2019 Nov 7]; 2(1):26-43. Available from: https://www.interdisciplinaremsaude.com.br/Volume_3/ Trabalho_03.pdf

4. Cruz SP, Abellán MV. Professional burnout, stress and job satisfaction of nursing staff at a university hospital. Revista Latino-Am. Enfermagem. [Internet]. 2015 Maio/Jun [cited 2019 Nov 7]; 23(3):543-52. Available from: http://www.scielo.br/scielo. php?script=sci_issuetoc\&pid=0104-116920150003\&lng=pt\&n$\mathrm{rm}=$ iso

5. Machado M, Oliveira E, Lemos W, Lacerda W, Filho W, Wermelinger M, Vieira M. Santos M. Junior P, Justino E, Barbosa C Mercado de trabalho da enfermagem: aspectos gerais. Enferm Foco [Internet]. 2016 [cited 2019 Nov 6];7(ed. espe.):35-53. Available from: http://revista.cofen.gov.br/index.php/enfermagem/ article/view/691.

6. Ximenes Neto FRG, Crispim FSP. Riscos à saúde de trabalhadores rurais no extrativismo da palha de carnaúba. Enferm Foco. [Internet]. 2019 [cited 2019 Nov 8]; 10(2)17-23: Available from: http:// revista.cofen.gov.br/index.php/enfermagem/article/view/2281
7. Organização Internacional do Trabalho (OIT). Programa de Actividades Sectoriales. Repertorio de recomendaciones prácticas sobre seguridad y salud em la agricultura. Ginebra $(\mathrm{CH})$ Oficina Internacional del Trabajo; 2010. [Internet]. 2019 [cited 2019 Nov 8]; Available from: http://www.ilo.org/wcmsp5/groups/ public/---ed_protect/---protrav/---afework/documents/normativeinstrument/wcms_112442.pdf .

8. Ministério do Trabalho (BR). Portaria N. $\cong 25$, de 29 de dezembro de 1994 - Aprova a Norma Regulamentadora n 9 - Riscos Ambientais, e dá outras providências. DOU de 30/12/1994 Seção 1, páginas 21.280 a 21.282. [Internet]. 1994 [cited 2019 Nov 6]. Available from:https://www.normasbrasil.com.br/norma/portaria-25-1994_180705.html.

9. Ministério da Saúde (BR). Resolução № 466/2012, de 13 de junho de 2013 do Conselho Nacional de Saúde/MS sobre Diretrizes e Normas Regulamentadoras de pesquisa envolvendo seres humanos. Diário Oficial da União. 2012. [cited 2020 Apr 12] Available from: http://conselho.saude.gov.br/resolucoes/2012/ Reso466.pdf

10. Machado MH, Aguiar Filho W. Lacerda WF, Oliveira E, Lemos W, Wermelinger $M$, et al.Características gerais da Enfermagem: o perfil sócio demográfico. Enferm Foco [Internet]. 2016 [cited 2019 Dez 3]; 7(ed. espe.):9-14. Available from: http://revista.cofen.gov.br/index.php/enfermagem/article/ view/686/296.

11. Trettene AS, Ferreira JAF, Mutro MEG, Tabaquim MLM, Razera APR. Estresse em profissionais de enfermagem atuantes em Unidades de Pronto Atendimento. Bol. - Acad. Paul. Psicol. [Internet]. 2016 Jul. [cited 2020 May 6]; 36(91):243-261. Available from: http://pepsic.bvsalud.org/scielo.php?script=sci_arttextEpid=S1415-711X2016000200002\&lng=pt\&nrm=iso

12. Jorge VC, Barreto MS, Ferrer ALM, Santos EAQ, Rickli HC 
Marcon SS. Equipe de enfermagem e detecção de indicadores de agravamento em pacientes de pronto-socorro. Esc. Anna Nery [Internet]. 2012 Dec [cited 2020 May 06]; 16(4):767-774. Available from: http://www.scielo.br/scielo.php?script=sci_arttextEpid=S1414-81452012000400018\&lng=en

13. Machado MH. [Coordenadora]. Pesquisa Perfil da Enfermagem no Brasil: Relatório Final. Rio de Janeiro: Nerhus-Daps-Ensp/ Fiocruz; 2017. [citado 2019 Ago 10]. Available from: www.ensp.fiocruz.br/observahr/

14. Silva AP, Carvalho ES, Cardim A. Trabalho noturno na vida dos enfermeiros. Revista Enfermagem Contemporânea. [Internet]. 2017 [cited 2020 May 5]; 6(2):177-185. Available from: https://www5. bahiana.edu.br/index.php/enfermagem/article/view/1292/1078.

15. Silveira M, Camponogara S, Beck CLC. As produções cientificas sobre o trabalho noturno na enfermagem: uma revisão da literatura. J. res.: fundam. Care. Online. 2016:8(1):3679-90. doi:10.9789/2175-5361.2016.v8i1.3679-3690.

16. Ministério do Trabalho e Emprego (BR). Riscos biológicos guia técnico: os riscos biológicos no âmbito da NR 32. Brasília (DF): MTE; 2008. [Internet]. 2008 [cited 2020 May 6]. Available from: https://www.unifesp.br/reitoria/dga/images/legislacao/biosseg/ guia_tecnico_cs3.pdf.

17. Ministério da Saúde (BR). Secretaria de Políticas de Saúde. Departamento de Atenção Básica. Área Técnica de Saúde do Trabalhador. Saúde do trabalhador. Brasilia: Ministério da Saúde: 2001. 63p. : il. - (Cadernos de Atenção Básica. Programa Saúde da Familia; 5). [Internet]. 2001 [cited 2020 May 6]. Available from: http://bvsms.saude.gov.br/bvs/publicacoes/saude_trabalhador_ cab5_2ed.pdf

18. Ministério da Saúde (BR). Organização Pan-Americana da Saúde (OPAS). Doenças relacionadas ao trabalho: manual de procedimentos para os serviços de saúde. Brasília: Ministério da Saúde; 2001. [internet] 2020 [cited 2020 May 6]. Available from: https://bvsms.saude.gov.br/dicas-em-saude/2323-saude-e-seguranca-no-trabalho

19. Ruas EFG, Santos LS, Barbosa LA, Belasco AGS, Bettencourt ARC. Acidentes Ocupacionais com Materiais Perfurocortantes em Hospitais de Montes Claros-MG. REME - Rev. Min. Enferm. [internet] 2012. [cited 2020 Apr 12]; 16(3): 437-443. Available from: http://www.reme.org.br/artigo/detalhes/547.

20. Sulzbacher E, Fontana RT. Concepções da equipe de enfermagem sobre a exposição a riscos físicos e químicos no ambiente hospitalar. Rev. bras. enferm. [Internet]. 2013 Feb [cited 2020 May 06]; 66(1):25-30. Available from: http://www.scielo.br/ scielo.php?script=sci_arttext\&pid=S0034-71672013000100004\&lng=en . http://dx.doi.org/10.1590/S0034-71672013000100004
21. Nishide VM, Benatti MCC. Riscos ocupacionais entre trabalhadores de enfermagem de uma unidade de terapia intensiva. Rev. esc. enferm. USP. [Internet]. 2004 Dec [cited 2020 May 06]; 38(4):406-414. Available from: http://www.scielo.br/scielo.php?script=sci_arttext\&pid=s0080-62342004000400006\&lng=en . http://dx.doi.org/10.1590/S0080-62342004000400006

22. Duarte NS, Mauro MYC. Análise dos fatores de riscos ocupacionais do trabalho de enfermagem sob a ótica dos enfermeiros. Rev. bras. saúde ocup. [Internet]. 2010 June [cited 2020 May 06]; 35(121):157-167. Available from: $\quad$ http://www.scielo.br/scielo.php?script=sci_arttextEpid=\$0303-76572010000100017\&lng=en

23. Monterio Jr AT. Riscos Ocupacionais e problemas de saúde associados às condições de trabalho de enfermagem em unidades intensivas hospitalares. Dissertação de Mestrado - Pós Graduação em Enfermagem da Universidade do Estado do Rio de Janeiro - 2010. [Internet]. 2010 [cited 2020 May 5]. Available from: http://www.bdtd.uerj.br/tde_busca/arquivo. php?codArquivo $=2700$

24. Ministério da Saúde (BR). Ambiência. [internet] 2020 [cited 2020 May 6]. Available from: https://bvsms.saude.gov.br/bvs/dicas/170_ambiencia.html.

25. Barbosa ASAA. Diogo GA, Salotti SRA, Silva SMUR. Subnotificação de acidente ocupacional em profissionais de Enfermagem. Rev Bras Med Trab. [Internet]. 2017 [cited 2020 May 6]: 15(1):12-7. Available from: http://www.rbmt.org.br/ details/209/pt-BR/subnotificacao-de-acidente-ocupacional-com-materiais-biologicos-entre-profissionais-de-enfermagem-em-um-hospital-publico

26. Moita MP, Ximenes Neto FRG, Silva RLB, Prado JÁ, Viana TB, Borges GD. Research, Society and Development. [Internet]. 2020 [cited 2020 May 6]; 9(5):el67953259. Available from: https://rsd. unifei.edu.br/index.php/rsd/article/view/3259.

27. Rodrigues BC, Moreira CCC, Triana TA, Rabelo JF, Higarashi IH. Limitações e consequências na vida do trabalhador ocasionadas por doenças relacionadas ao trabalho. Rev Rene. [Internet]. 2013 [cited 2020 May 6]; 14(2):448-457. Available from: http://www. redalyc.org/articulo.oa?id=324027986021.

28. Ximenes Neto FRG, Braga FRR, Marques JPC, Moreira KB, Oliveira AVPG, Cunha MC et al. Epidemiology of RSI / WRMD in Northwest Ceará, 2009 to 2016. International Journal Of Development Research. [Internet]. 2018 [cited 2020 May 6]: 8(8):2249222499. Available from: https://www.journalijdr.com/epidemiology-rsi-wrmd-northwest-cear\%C3\%Al-2009-2016.

29. Dejours C. O fator humano. 5. ed. 13a reimp. Rio de Janeiro: Editora da Fundação Getúlio Vargas; 2013. 